О. А. Серков ${ }^{1}$, К. А. Трубчанінова ${ }^{2}$, Б. О. Лазуренко ${ }^{1}$

${ }^{1}$ Національний технічний університет «Харківський політехнічний інститут», Харків, Україна

2 Український державний університет залізничного транспорту, Харків, Україна

\title{
ЗАВАДОСТІЙКІСТЬ МОБІЛЬНИХ ТЕЛЕКОМУНІКАЦІЙНИХ СИСТЕМ
}

\begin{abstract}
Анотація. Предметом вивчення є процеси забезпечення завадостійлості мобільних телекомунікаційних систем на грунті надширокосмугових сигналів з високою інформаційною ємністю. Мета - розробка рекомендацій щодо забезпечення завадостійкості надширокосмугової системи зв'язку при передачі дискретних повідомлень каналом зв'язку з адитивним гаусовим шумом. Задача - забезпечення усталеної та надійної роботи надширокосмугової системи зв'язку. Використані методи: методи аналітичного моделювання та теорії потенціїної завадостійкості. Отримані наступні результати. Розроблено критерій забезпечення завадостійкості мобільних телекомунікаційних систем. На грунті теорії потенціальної завадостійкості показана можливість усталеної та беззавадової роботи телекомунікаційної безпроводової системи в умовах, коли рівень інформаційного сигналу та шуму мають одне значення. Доведена можливість вилучення переданого інформаційного сигналу із суміші шуму та корисного сигналу шляхом кореляції прийнятого та опорного сигналів. Показана можливість розрізнення двох сигналів на фоні шуму, які найбільш імовірно було передано та прийнято по каналу зв' язку з білим гаусовим шумом. Висновки. Показано, що використання технології надширокосмугових сигналів дозволяє здійснити безпроводову приховану передачу інформації з малою потужністю випромінювання. Причому велика база сигналу $B \geq 2.5$ дозволяє забезпечити усталену та беззавадову роботу телекомунікаційної системи за умов, коли рівень інформаційного сигналу знаходиться на рівні $(q=1)$ чи нижче рівня шуму. При цьому доведена можливість вилучення як корисного сигналу із суміші сигналу та шуму, так і визначення з подальшим вилученням одного вірогідного сигналу із суміші двох повністю відомих сигнала $s_{0}(t), s_{1}(t)$ із білим гаусовим шумом.
\end{abstract}

Ключов і сл ов а: рухомий зв'язок; завадостійкість; база сигнала; критерій завадостійлості; кореляція.

\section{Ветуп}

Проблема завадостійкості є однією з найбільш пріоритетних в сучасній безпроводовій техніці зв'язку. До традиційних засобів забезпечення завадостійкості відносять частотне планування, контроль за яким здійснюють національні та міжнародні інститути, використання антен із вузькою діаграмою спрямованості та інше. Розвиток технологій мобільних пристроїв, безпроводових персональних локальних мереж (wireless personal area networks WPAN) та стрімкий розвиток Internet викликає все більшу нагальну потребу у підвищенні ємності мобільних мереж, для яких особливе значення мають низька вартість обладнання та незначне енергоспоживання. При цьому основною тенденцією їх розвитку є уніфікація персональних засобів комунікації, що означає можливість використання одного терміналу для з’єднання з інформаційними службами в різноманітних середовищах. У свою чергу це викликає потребу в отриманні високошвидкісних безпроводових систем зв'язку, що вимагає ефективного використання електромагнітного спектру $[1,2]$. У той же час нагальною стає проблема забезпечення завадостійкості рухомих мобільних безпроводових пристроїв, що обумовлено вимогами до високої щільності каналів зв'язку на один квадратний метр робочої зони, їх пропускної здатності та завадостійкості в умовах дії ненавмисних та навмисних завад.

Особливість забезпечення завадостійкості в системах безпроводового зв'язку обумовлена необхідністю організації радіодоступу багатьох користувачів до обмеженого ресурсу - середовища передачі. Існує низка методів, які базуються на розподілі між окремими засобами мобільного зв'язку таких параметрів, як частота, час, код і простір із мінімумом взаємних завад та максимальним використанням характеристик середовища передачі. Зробити інформаційний сигнал випромінювання непомітним для будь-яких приймачів, окрім того, кому його призначено, можливо за рахунок ускладнення закону модуляції та шляхом розширення його спектру. Такий сигнал майже не здатен чинити небажаний вплив на звичайну сторонню систему, яка працює в тій же смузі частот. Однак основним методом забезпечення завадостійкості в системах безпроводового мобільного зв'язку є зниження рівня електромагнітних полів [3-5]. При цьому задача полягає в обранні такого виграшу від обробки сигналу, який би гарантував достатньо низький рівень його спектральної щільності $N_{S}$ відносно спектральної інтенсивності природного шуму $N_{0}$ на вході приймача.

\section{Критерій забезпечення завадостійкості мобільних телекомунікаційних систем}

Забезпечити необхідний рівень завадостійкості телекомунікаційних систем рухомого зв'язку, здатна технологія надширокосмугового зв'язку. Суть її полягає у передачі малопотужних кодованих імпульсів в дуже широкій смузі частот без несучої частоти. Причому широкосмужність системи визначає не абсолютна величина ширини використаної смуги частот, а співвідношенням спектру повідомлення, який визначено швидкістю отримання інформації, та шириною спектра сигнала [6]. Припустимо, що $\Delta F \epsilon$ шириною спектру повідомлення, $W$ - ширина спектру сигнала, а $T$ - тривалість сигнала. Добуток $B=W T$ є базою сигналу. Зазвичай для широкосмугових систем $\mathrm{W}>>\Delta F$ та $B>>1$. Розширюючи смугу частот із $\Delta F$ до $W$ виникає можливість збільшення швидкості передачі інформації, укорочуючи передані сигнали з величини $T \cong 1 / \Delta F$ до $T_{1} \cong 1 / W$, причому $T_{1}<T$. Таким чином до переданого сигналу вводять деяку надмірність, величину якої визначає кое- 
фіцієнт розширення спектру $K_{f} \cong W / \Delta F$. Саме наявність цієї надмірності визначає такі властивості надширокосмугових систем, як можливість переборення явища багатопроменевості, усталеність до завад, та можливість ефективного використання спектру під час використання перевантаженого частотного діапазону та цифрової обробки сигналу.

Зазвичай, нижня межа співвідношення спектральних щільностей сигналу $N_{S}$ та завади $N_{0}$ у -7 дБ на вході приймача гарантує його нормальну роботу. Цей рівень відповідає співвідношенню:

$$
N_{S} / N_{0} \leq 0.2
$$

$\mathrm{У}$ той же час спектральну щільність $N_{S}$ визначають наступним співвідношенням:

$$
N_{S}=P / W=E /(W T),
$$

де $F$ - потужність сигналу; $W$ - ширина спектру сигналу; $E$ - енергія сигналу; $T$ - тривалість сигналу. Таким чином, з урахуванням (1), (2) критерієм завадостійкості стає вирішення наступної нерівності:

$$
E /(W T) \leq 0.2 \text {. }
$$

Згідно теорії потенціальної завадостійкості Котельнікова В.А. [7] характеристики інформаційного сигналу залежать від відношення подвійної енергії сигналу $E$ до спектральної щільності потужності шуму $N_{0}$ та складає величину:

$$
Q=2 E / N_{0}=2 q_{0} B,
$$

де $q_{0}=(E / T) /\left(N_{0} W\right)$ - відношення середньої потужності сигналу $P_{S 0}=E / T$ до потужності шуму $P_{N 0}=N_{0} W$ на вході приймача, а $B=W T \in$ базою сигналу. При цьому (3) прийме такого вигляду:

$$
q^{2} /(W T) \leq 0.4,
$$

де сам критерій визначено у термінах відношення сигнал / шум на вході приймача $q$ та виграшу від обробки $W T$.

Зниження рівня електромагнітного випромінювання $\epsilon$ основним методом забезпечення завадостійкості в системах безпроводового мобільного зв'язку. Тому сприйнятливим щодо забезпечення усталеної беззавадової роботи є зниження інформаційного сигналу на вході приймача до рівня шуму $(q=1)$. Це обумовлює критерій щодо забезпечення завадостійкості телекомунікаційних систем безпроводового мобільного зв'язку $(W T \geq 2.5)$. Таким чином, для забезпечення завадостійкості безпроводових мобільних систем найбільш доцільним є застосування технології надширокосмугових сигналів 3 базою сигналу $B \geq 2.5$. При цьому виникає задача вилучення інформаційнрго сигналу на фоні шуму.

\section{Виявлення сигналу на фоні шуму}

Вилучення корисного сигналу на фоні шуму здійснюють шляхом кореляції прийнятого та опорного сигналів. Корелятор виконує згортку прийнятого сигналу з еталонним. Він $є$ ідеальним детектором для визначення часових зсувів прийнятих імпульсів відносно опорних. Так при прийомі одиниці кореляційна функція дорівнює +1 , а при прийомі 0 - приймає значення -1. У будь-яких інших випадках кореляційна функція дорівнює 0. Накопичення в кореляторі приймача певної кількісті надкоротких імпульсів, що кодують кожен з інформаційних бітів, дають можливість суттєво підвищити співвідношення сигнал/шум, забезпечуючи можливість передачі інформації в широкому частотному діапазоні значно нижче рівня білого шуму, забезпечуючи при цьому вимоги щодо завадостійкості рухомих мобільних пристроїв.

Реальні повідомлення зазвичай є нестаціонарними, тому їх моделі також є нестаціонарними випадковими процесами, які припускають квазістаціонарну трактовку. Їх можна вважати практично стаціонарними на проміжках часу невеликої тривалості. Перехід до стаціонарної моделі обумовлено тим, що вирішення задач із урахуванням нестаціонарності повідомлень викликає ускладнення та вимагає складного математичного апарату. Тому у якості стаціонарних моделей повідомлень, сигналів і завад використовують гаусівський випадковий процес, який однозначно визначає математичне очікування $\boldsymbol{m}$ та кореляційна функція $R(\tau)$.

Використання надширокосмугових сигналів надає безпроводовому каналу зв'язку такі вади, як високу завадозахищеність, уникнення завмирань сигналу в каналах із багатопроміневістю, забезпечення багатостанційного доступу 3 одночасною роботою багатьох радіотехнічних систем в одному й тому ж діапазоні частот, забезпечення електромагнітної сумісності з вузькосмуговими радіотехнічними системами. Причому надширокосмуговими вважаємо такі сигнали, для яких виконується співвідношення:

$$
B=F_{C} T_{C}>>1,
$$

де $B, F_{C}, T_{C}$ - база, ширина спектру і тривалість сигналу відповідно.

Імовірнісний метод передачі інформації полягає у застосуванні кореляційного методу для обробки сигналів, які на вході приймача мають вигляд.

$$
u(t)=\lambda s(t)+n(t)
$$

де $u(t)$ - прийнятий сигнал; $s(t)$ - корисний сигнал; $n(t)$ - гаусівський шум; $\lambda$ - випадкова величина, що приймає значення 1 чи 0 із імовірностями $p$ чи $1-p$ відповідно.

Щоб за прийнятим сигналом $u(t)$ на фоні гаусівського адитивного шуму $n(t)$ із спектральною щільністю $N_{0}$ в смузі пропускання приймача $\Delta f$ вирішити, чи є у наявності корисний сигнал $s(t)$ слід обчислювати відношення функцій правдоподібності $l(u)=W\left(u / H_{1}\right) / W\left(u / H_{0}\right)$ та порівнювати його із деяким порогом $l_{0}$, який визначено за критерієм ідеального спостерігача: $l_{0}=(1-p) / p$.

Критерій ідеального спостерігача обрано тому, що будь - які помилки під час прийому символів небажані, та втрати, пов'язані з цими помилками, однакові. Функції $W\left(u / H_{1}\right)$ та $W\left(u / H_{0}\right) \in$ функціями правдоподібності. У випадку наявності корис- 
ного сигналу справедливою є гіпотеза $H_{1}$, а у випадку його відсутності - справедлива гіпотеза $H_{0}$. Логарифм відношення функцій правдоподібності має наступний вигляд:

$$
\ln l(u)=\frac{E}{N_{0}}+\frac{2}{N_{0}} \int_{0}^{T} u(t) s(t) d t,
$$

де: $E$ - енергія сигналу; $T$ - тривалість сигналу.

3 урахуванням цього співвідношення слід обчислити інтеграл:

$$
q=\frac{2}{N_{0}} \int_{0}^{T} u(t) s(t) d t
$$

та порівняти його значення з порогом:

$$
z_{0}=\ln l_{0}+E / N_{0} .
$$

При перевищенні порогу, рішення приймається на користь гіпотези $H_{1}$, у іншому випадку - на користь гіпотези $H_{0}$. Таким чином співвідношення (1) $\epsilon$ мірою взаємної кореляції між прийнятим сигналом $u(t)$ та очікуваним корисним сигналом $s(t)$. Умовні імовірності хибного визначення $\alpha$ і пропуску $\beta$ сигналу визначають такі співвідношення:

$$
\begin{aligned}
& \alpha=p\left\{q \geq \ln l_{0}+\frac{E}{N_{0}} / H_{0}\right\}=\int_{-\infty}^{\infty} W\left(q / H_{0}\right) d q, \\
& \beta=p\left\{q<\ln l_{0}+\frac{E}{N_{0}} / H_{1}\right\}=\int_{-\infty}^{z_{0}} W\left(q / H_{1}\right) d q,
\end{aligned}
$$

де: $W\left(q / H_{1}\right)$ та $W\left(q / H_{0}\right)$ - розподілення напруги на вході кореляційного приймача за умов справедливості гіпотез $H_{1}$ та $H_{0}$ відповідно.

Із урахуванням співвідношення (1) отримуємо:

$$
\begin{gathered}
W\left(q / H_{0}\right)=\frac{1}{\sqrt{2 \pi \cdot 2 E / N_{0}}} \exp \left(-q^{2} /\left(4 E / N_{0}\right)\right), \\
W\left(q / H_{1}\right)=\frac{1}{\sqrt{2 \pi \cdot 2 E / N_{0}}} \exp \left(-\left(q-\frac{2 E}{N_{0}}\right)^{2} /\left(2 \frac{2 E}{N_{0}}\right)\right) .
\end{gathered}
$$

Таким чином умовні імовірності хибного визначення сигналу $\alpha$ та пропуску сигналу $\beta \epsilon$ такими.

$$
\begin{gathered}
\alpha=\int_{Z_{0}}^{\infty} \frac{1}{\sqrt{2 \pi \frac{2 E}{N_{0}}}} \exp \left(-\frac{q^{2}}{2 \frac{2 E}{N_{0}}}\right) d q=1-\Phi\left(\frac{\ln l_{0}+\frac{E}{N_{0}}}{\sqrt{\frac{2 E}{N_{0}}}}\right) ; \\
\beta=\int_{-\infty}^{Z_{0}} \frac{1}{\sqrt{2 \pi \cdot 2 E / N_{0}}} \exp \left(-\left(q-\frac{2 E}{N_{0}}\right)^{2} /\left(2 \frac{2 E}{N_{0}}\right)\right) \mathrm{dq}= \\
=\Phi\left(\left(\ln l_{0}+E / N_{0}\right) / \sqrt{2 E / N_{0}}\right),
\end{gathered}
$$

де $\Phi(x)=\frac{1}{2 \pi} \int_{-\infty}^{x} \exp \left(-z^{2} / 2\right) d z-$ інтеграл імовірності.

\section{Розрізнення двох відомих сигналів на фоні білого шуму}

Сигнал на вході приймача являє суму завади та одного з двох відомих сигналів. Задача полягає у тому, щоб по прийнятій суміші сигналів вирішити, який 3 сигналів передається. Цифровий двійковий код передбачає визначення двох повністю відомих сигналів $s_{0}(t)$ та $s_{1}(t)$ на фоні білого гаусівського шуму. У цьому випадку сигнал на вході приймача.

$$
u(t)=\lambda s_{1}(t)+(1-\lambda) s_{0}(t)+n(t),
$$

де $u(t)$ - прийнятий сигнал; $s(t)$ - корисний сигнал; $n(t)$ - гаусівський шум із спектральною щільністю $N_{0} ; \lambda$ - випадкова величина, що приймає значення 1 чи 0 із імовірностями $p$ чи 1- $p$ відповідно.

Необхідно за прийнятим сигналом $u(t)$ визначити, який 3 корисних сигналів $s_{0}(t)$ чи $s_{1}(t)$ передавався. Таким чином слід здійснити вибір між гіпотезою $H_{0}$, коли в наявності сигнал $s_{0}(t)$ чи альтернативною гіпотезою $H_{1}$, коли в наявності сигнал $s_{1}(t)$. За критерій оптимальності також обрано критерій ідеального спостерігача. При цьому рішення приймається на користь гіпотези $H_{1}$, коли $l(u) \geq l_{0}$, чи на користь гіпотези $H_{0}$ коли $l(u)<l_{0}$. У цьому випадку логарифм відношення правдоподібності визначається як:

$$
\ln l(u)=\frac{E_{1}-E_{0}}{N_{0}}+\frac{2}{N_{0}} \int_{0}^{T} u(t)\left[s_{1}(t)-s_{0}(t)\right] d t,
$$

де $E_{1}$ та $E_{0}$ - енергія сигналів $s_{0}(t)$ та $s_{1}(t)$ відповідно. Зазвичай, $E_{1}=E_{0}$, а $p=1 / 2$. При цьому рішення приймається на користь сигналу $s_{1}(t)$, коли

$$
q=\frac{2}{N_{0}} \int_{0}^{T} u(t)\left[s_{1}(t)-s_{0}(t)\right] d t \geq 0 .
$$

Середня імовірність похибки для випадку рівноімовірних сигналів матиме наступний вигляд:

$$
P_{p}=(\alpha+\beta) / 2 \text {, }
$$

де $\alpha=\int_{\ln l_{0}}^{\infty} W\left(q / H_{0}\right) d q, \beta=\int_{-\infty}^{\ln l_{0}} W\left(q / H_{1}\right) d q-$ умовні імовірністі щодо прийняття рішення про наявність сигнала $s_{1}(t)\left(s_{0}(t)\right)$, у той час, коли у дійсності передавався сигнал $s_{0}(t)\left(s_{1}(t)\right)$.

Знайдемо імовірності $\alpha$ та $\beta$. Визначимо щільності імовірностей $W\left(q / H_{1}\right)$ і $W\left(q / H_{0}\right)$. Випадкова величина $q$ за наявності сигнала $s_{1}(t)$.

$$
q=q_{1}=\frac{2}{N_{0}} \int_{0}^{T}[s(t)+n(t)]\left[s_{1}(t)-s_{0}(t)\right] d t .
$$

3 урахуванням того, що $n(t)$ - гаусівський шум, сигнали $s_{0}(t)$ та $s_{1}(t)$ - детерміновані функції, а усі операції, які здійснюються у цьому співвідношенні лінійні, то випадкова величина $q_{1}$ буде розподілена за нормальним законом. Її середнє значення буде: 


$$
M\left\{q_{1}\right\}=2 E\left(1-R_{S}\right) / N_{0} .
$$

Дисперсію визначає таке співвідношення:

$$
\begin{gathered}
\sigma_{q_{1}}^{2}=\frac{4 E\left(1-R_{S}\right)}{N_{0}}, \\
q_{1}=\frac{2}{N_{0}} \int_{0}^{T}[s(t)+n(t)]\left[s_{1}(t)-s_{0}(t)\right] d t .
\end{gathered}
$$

\section{Аналіз}

Аналіз проблеми забезпечення вимог завадостійкості рухомих мобільних безпроводових пристроїв показав, що основним методом іiі вирішення $\epsilon$ зниження рівня випромінювання електромагнітних полів. На грунті теорії потенціальної завадостійкості Котельнікова В.А. показана можливість усталеної та беззавадової роботи телекомунікаційної безпроводової системи в умовах, коли рівень інформаційного сигналу та шуму мають одне значення. Показана можливість вилучення переданого інформаційного сигналу із шуму шляхом кореляції прийнятого та опорного сигналів, а також визначити, який 3 двох переданих корисних сигналів найбільш імовірно було передано та прийнято.

\section{Висновки}

Використання технології надширокосмугових сигналів дозволяє здійснити безпроводову приховану передачу інформації з малою потужністю випромінювання. Застосування великої бази сигналу $B \geq 2.5$ дозволяє забезпечити усталену та беззавадову роботу телекомунікаційної системи за умов, коли рівень інформаційного сигналу знаходиться на рівні чи нижче рівня шуму $(q=1)$. При цьому, доведена можливість вилучення шляхом кореляції прийнятого та опорного сигналів як корисного сигналу на фоні шуму, так і двох повністю відомих сигнала $s_{0}(t)$ та $s_{1}(t)$ на фоні білого гаусівського шуму.

\section{Вдячність}

Цю роботу було частково профінансовано Свропейським Союзом у контексті проекту «dComFra - Digital competence framework for Ukrainian teachers and other citizens» (Project Number: 598236-EPP-12018-1-LT-EPPKA2-CBHE-SP) за програмою ERASMUS+. Підтримка Свропейською Комісією створення цієї роботи не означає повного схвалення ії змісту, який віддзеркалює лише погляди авторів. Комісія не може нести відповідальності за будь-яке використання інформації, яку розміщено в цій роботі.

\title{
СПИСОК ЛІТЕРАТУРИ
}

1. Соколова М.В. Сверхширокополосная беспроводная связь: история и перспективы развития. - Т-Сотт: Телекоммуникации и транспорт. -2008. -C-50-55.

2. Аджемов С.С., Соколова М.В., Урядников Ю.Ф., Штыркин В.В. Сверхширокополосная связь - результат развития технологий широкополосного доступа. - Электросвязь, 2006. — №2. - c. 18-23

3. Serkov, A. Noise-like signals in wireless information transmission systems / A. Serkov, V. Breslavets, M. Tolkachov, G. Churyumov, Issam Saad // Advanced Information Systems. - 2017. - Vol. 1, №2 - P. 33 - 39, available at: https://doi.org/10.20998/2522-9052.2017.2.06.

4. Рішення Федеральної комісії по зв’язку (FCC) США № FCC 02-48 від 14/02/2002 [Електронний ресурс]. - Режим доступу : https://apps.fcc.gov/edocs public/attachmatch/FCC-02-48A1.pdf. - Дата доступу :31.12.2019.

5. Serkov, O. A. (2019). On the issue of solving the problem of electromagnetic compatibility of the wireless telecommunication Systems / O. A. Serkov, G. I. Churyumov // Applied Radio Electronics. - 2017. - Vol. 16 № 3, 4. - P. 117-121.

6. Serkov A., Trubchaninova K., Mezitis M. (2019), Method of wireless transmission of digital information on the basis of ultra-wide signals, Advanced Information Systems, Vol.3, No. 4. pp. 33-38, available at: https://doi.org/10.20998/25229052.2019.4.04.

7. Котельников В.А. Теория потенциальной помехоустойчивости. - М.: Госэнергоиздат, 1956. - $151 \mathrm{c}$

Received (Надійшла) 27.02.2020 Accepted for publication (Прийнята до друку) 15.04.2020

\section{Noise stability of mobile telecommunication systems}

\author{
A. Serkov, K. Trubchaninova, B. Lazurenko.
}

Abstract. The subject of study is the processes of ensuring electromagnetic compatibility of mobile telecommunication systems based on ultra-wideband signals with high information capacity. The goal is to develop recommendations for ensuring electromagnetic compatibility of an ultra-wideband communication system when transmitting discrete messages by a communication channel with additive Gaussian noise. The task is to ensure the stable and reliable operation of an ultra-wideband communication system. Methods used: methods of analytical modeling and theory of potential noise immunity. The following results are obtained. A criterion for ensuring the requirements of electromagnetic compatibility of mobile telecommunication systems has been developed. Based on the theory of potential noise immunity, the possibility of stable and interference-free operation of a telecommunication wireless system in conditions where the level of the information signal and noise have the same value is shown. The possibility of removing the transmitted information signal from the mixture of noise and the useful signal by correlating the received and reference signals is proved. The possibility of distinguishing two signals against the background of noise is shown; it was most likely transmitted and received through a communication channel with white Gaussian noise. Conclusions. It is shown that the use of ultra-wideband signal technology allows wireless covert transmission of information with low radiation power. Moreover, a large signal base $B \geq 2.5$ allows for stable and interference-free operation of the telecommunication system in conditions when the level of the information signal is at the level $(q=1)$ or below the noise level. At the same time, the possibility of extracting both the useful signal and the sum of the signal and noise, and the determination with the subsequent removal of one possible signal from the mixture of two completely known signals, $s_{0}(t), s_{1}(t)$ with white Gaussian noise, is proved.

Keywords : mobile communications; noise immunity; signal base; noise stability criterion; correlation. 